\title{
The Context and Principles of Environmental Management System Implementation
}

\author{
DUMITRASCU A.-E. \\ Department of Manufacturing Engineering \\ Transilvania University of Brasov \\ 29 Eroilor Street, 500036, Brasov \\ ROMANIA \\ dumitrascu_a@unitbv.ro
}

\begin{abstract}
The purpose of this paper is to detail the aspects regarding the implementation requirements of environmental management system in accordance with SR EN ISO 14001:2015. There are defined the main indicators underlying the context and the principles of environmental management system highlighting the importance of systematic approach of environmental management. The presented study consists of environmental aspects assessment specific to the production processes. By implementing the adequate corrective actions, the score of the significant environmental aspects decrease falling within the category of insignificant environmental aspects.
\end{abstract}

Key-Words: - Environmental management system, sustainable development, significant environmental aspects.

Received: May 12, 2020. Revised: June 29, 2020. 2nd Revised: August 21, 2020.

Accepted: August 25, 2020. Published: August 26, 2020.

\section{Introduction}

The organizations around the world and their partners are aware of the issues related to environmental management [1], the costs associated with the impacts of environmental issues, the importance of addressing a responsible attitude and sustainable development. In this regard, government organizations and regulators are increasingly using international standards to establish the framework for ensuring compliance and coherence at national and international level [1].
The purpose of the international standard ISO $14001: 2015$ is to provide to organizations a framework to protect the environment and respond to changes in environmental conditions in balance with socio-economic needs. A systematic approach of environmental management can lead to the identification of options in order to contribute to sustainable development. In this sense, it is essential to achieve a balance between the main indicators (Fig. 1).

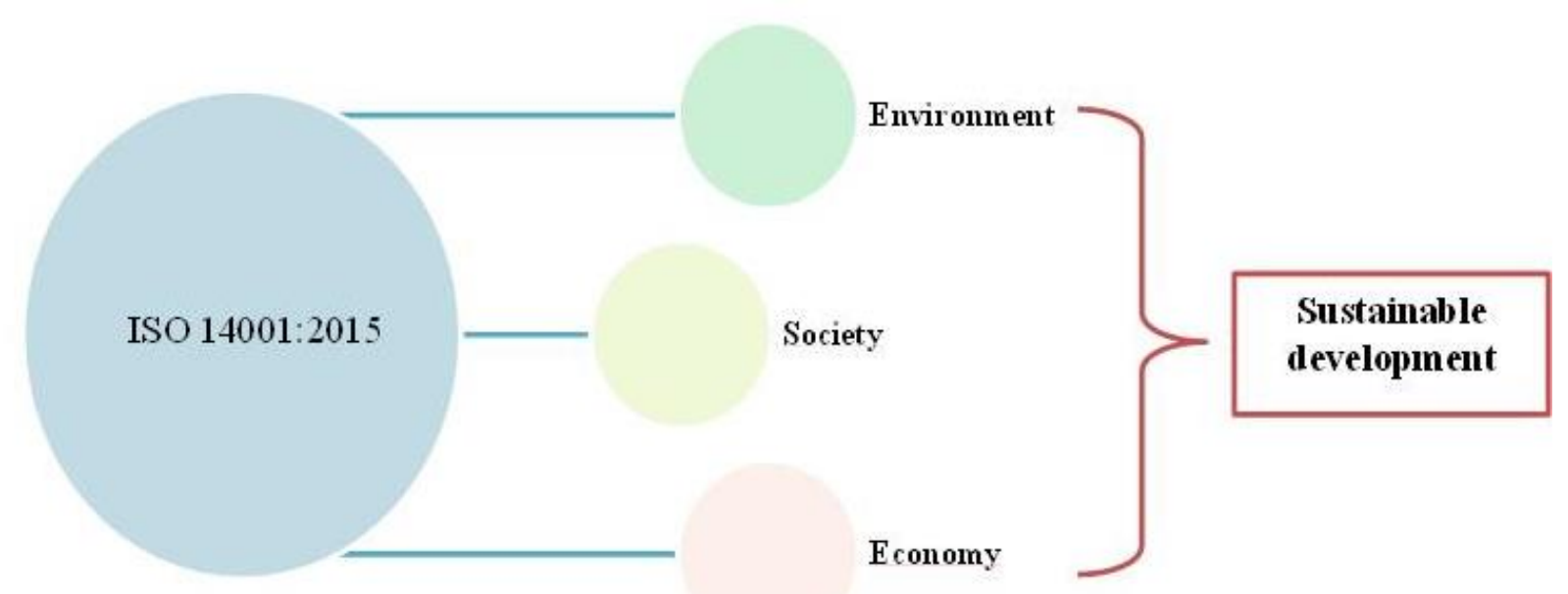

Fig. 1 The context of sustainable development

The concept of sustainable development represents all forms and methods of socio-economic development which basis is primarily a balance between the socio-economic systems and elements of natural capital. A model of sustainable development that specifies the main indicators underlying this principle is presented in figure 2 [2], [3]. 


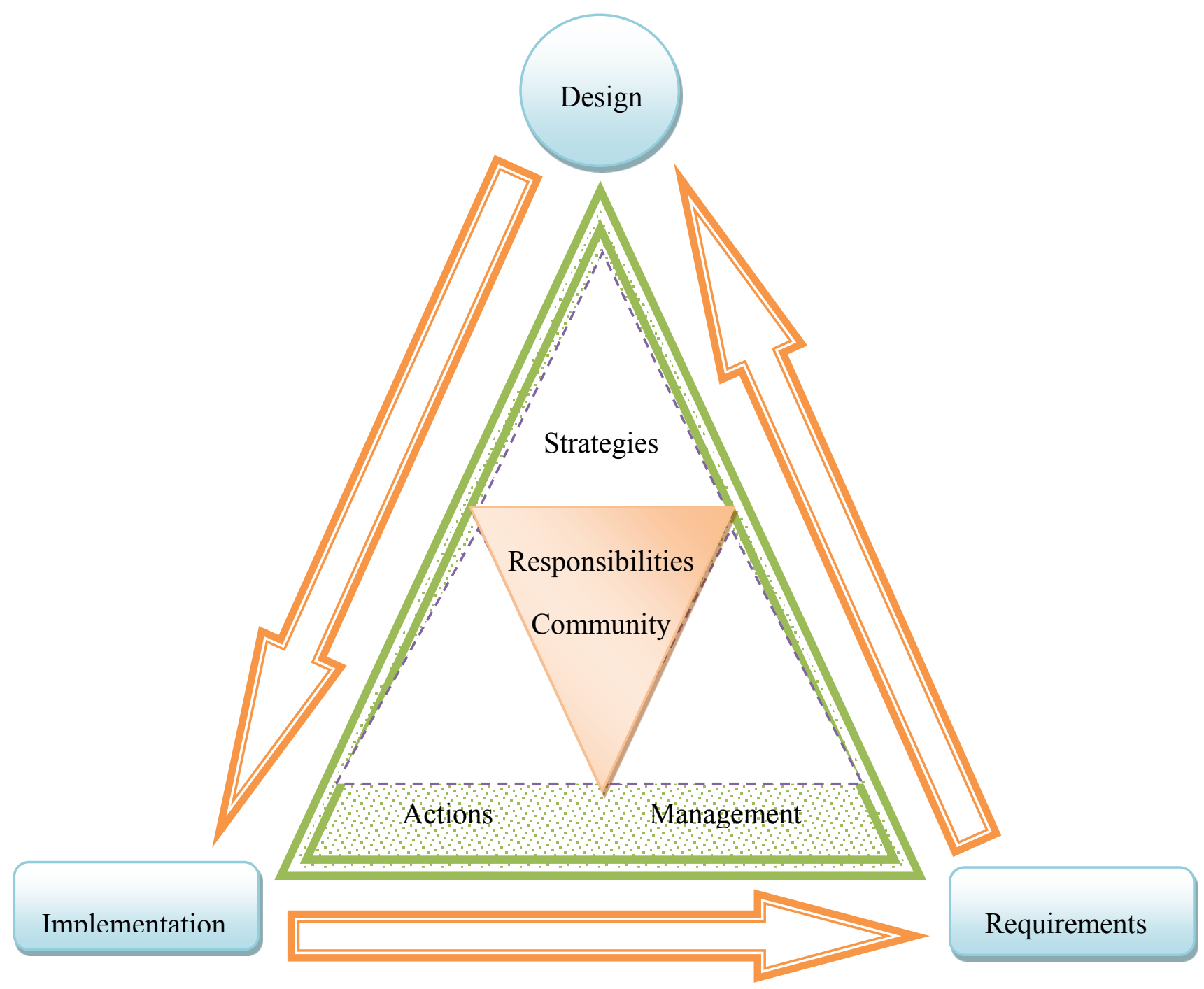

Fig. 2 Sustainable development model

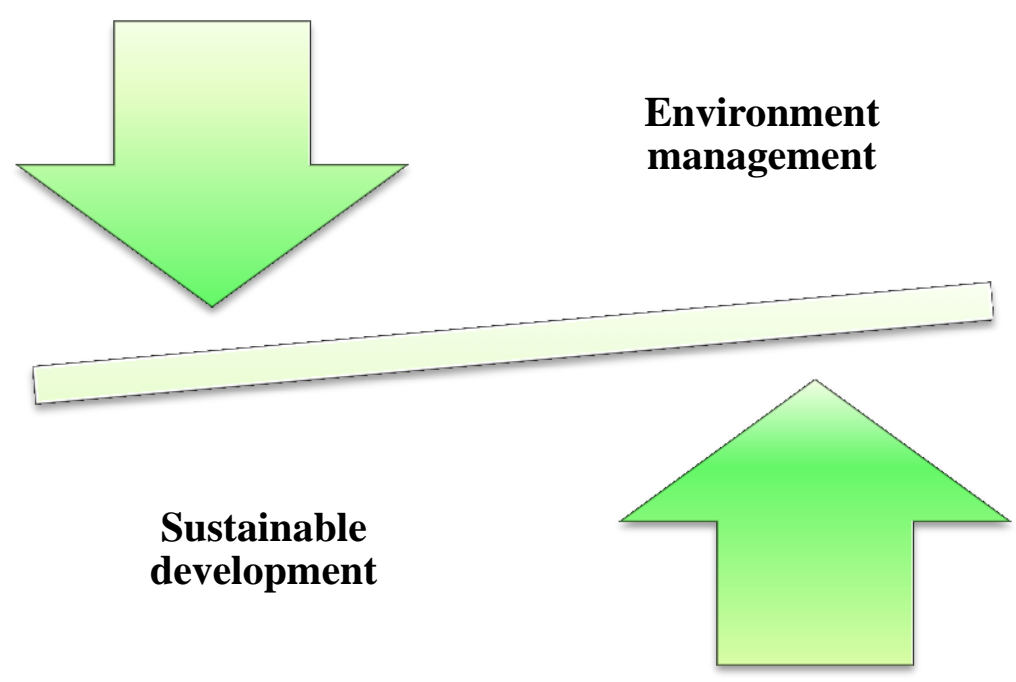

Fig. 3 Systematic approach of environmental management 
The development of increasingly restrictive legislation and regulations in the field of environmental management, the awareness of ensuring waste management effectively, valorization of resources and the use of advanced technologies have influenced the systemic approach of environmental management by organizations (Fig. 3).

\section{Environment Management System Implementation}

An environmental management system (EMS) is that component of the general management system of the organization consisting of the organizational structure, planning, responsibilities, processes, procedures and resources that support to elaborate, implement, review and maintain the environmental policy of the organization. The EMS allows the organization not only to meet the expectations regarding its environmental performance, but also to control its costs and comply with environmental legislation and regulations.

ISO 14001:2015 is applicable to any organizations, regardless of types, size and nature of activities. Environmental management system applies to the environmental aspects of its operations, products, and services that the organization sets that can control and or influence by taking account of the perspective of the life cycle [4]. EMS offers support to organizations in order to identify, manage, monitor, and control their environmental issues. It requires that an organization considers all environmental issues relevant to its operations.

Despite the fact that ISO 14001:2015 is not mandatory, it specifies a compliance commitment with the current environmental regulation. The basic principle of ISO 14001:2015 norms is continuous improvement of environmental performance following the steps of the Deming cycle: PDCA.

The specific requirements of an environmental management system according to ISO 14001 refer to environmental policy (Chapter 5), planning (Chapter 6), implementation (Chapter 7 - Support), operation (Chapter 8), verification (Chapter 9 Performance appraisal), and improvement (Chapter 10) [5], [6], [7].

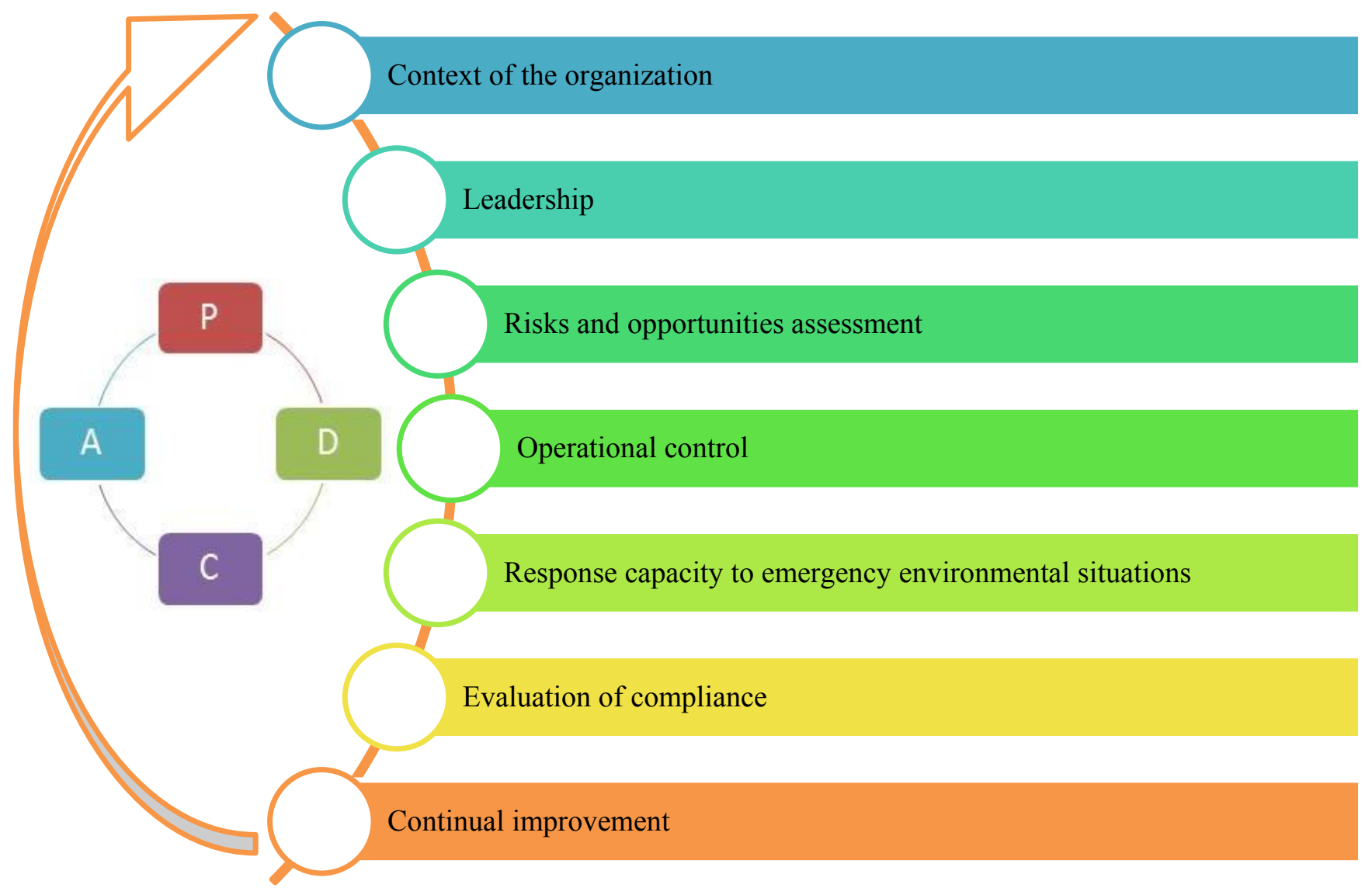

Fig. 4 The requirements of the ISO 14001:2015 
This study describes the assessment of environmental aspects of the generated waste as a result of specific activities to manufacturing processes, so as to ensure compliance with legal and other requirements. The identified environmental aspects are evaluated taking into account the generating source (activity, technological phase, equipment) and operating conditions (Fig. 5). Significant environmental aspects are monitored and controlled by implementing appropriate corrective actions in order to treat them. The procedure is applied to all activities that generate significant environmental issues relating to the generation, handling, storage, recovery or disposal of waste.

The assessment of environmental aspects specific to the production processes reveals that 10 environmental aspects have a significant impact on the environment. As a result of the implementation of corrective actions, the score of the significant environmental aspects decreased, they fall within the category of insignificant environmental aspects (Fig. 5).

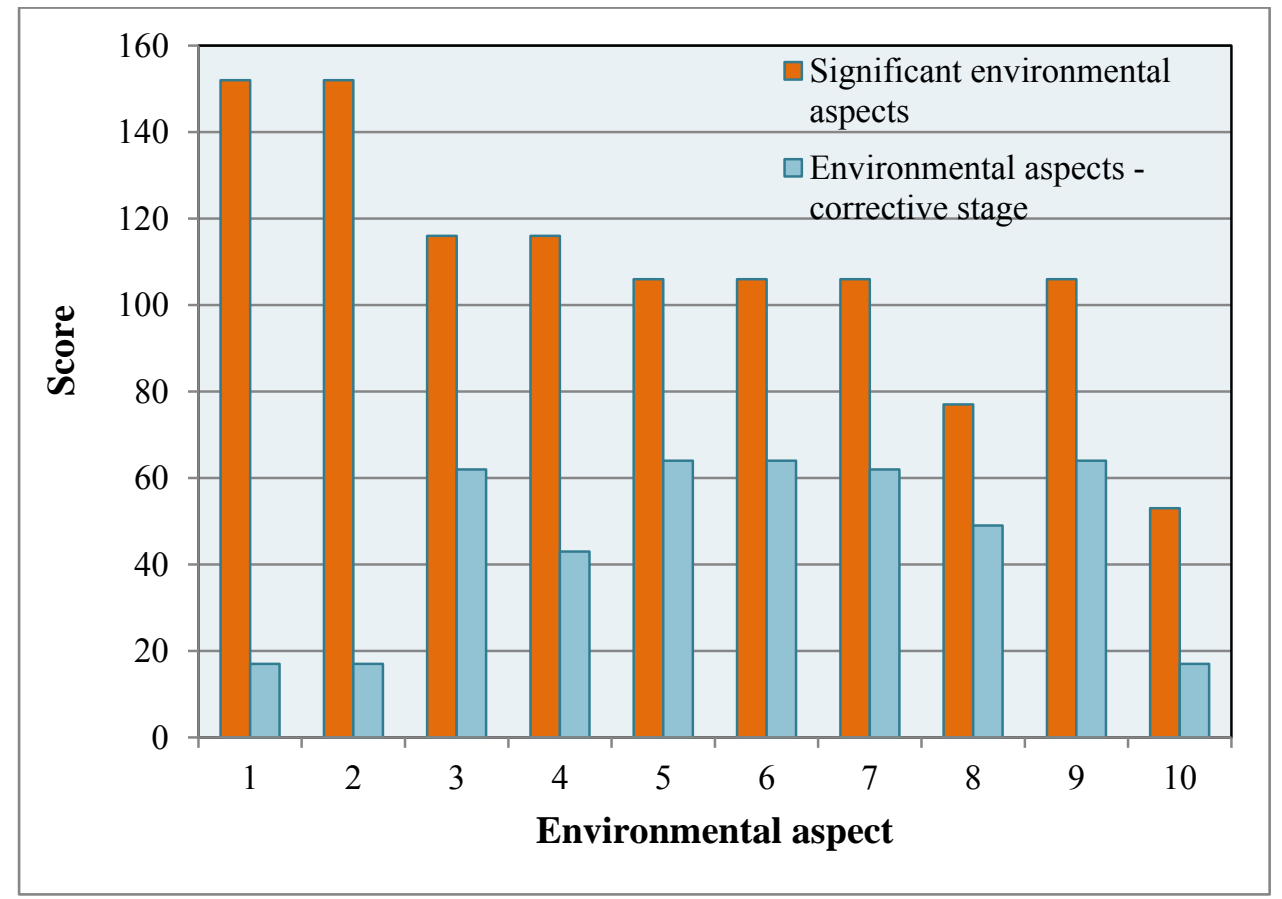

Fig. 5 Environmental aspects assessment

\section{Conclusions}

ISO 14001:2015 standard specifies the minimum requirements of the environmental management system in enterprises in order to control the environmental impact of its products, services and operations. The purpose of implementing an environmental management system is to continuously improve the efficacy of the system in order to increase environmental performance.

ISO 14001:2015 can be used by an organization in order to manage its environmental responsibilities in a systematic manner that contributes to the environmental pillar of sustainability.

A systematic approach of environmental management will contribute to sustainable development by:

- prevention or minimization of harmful impacts on the environment;
- minimizing the potential harmful effects of environmental conditions on the organization;

- compliance of the organization regarding the regulations imposed in the field of environmental management;

- improving of environmental performance.

- minimizing / preventing the environmental impacts from being transferred unintentionally;

- credibility on the competitive market;

- financial benefits;

- communicating of environmental information to all stakeholders.

Implementing an environmental management system will provide the following benefits:

- improving the relations with public authorities and with the socio-economic community;

- limitation of civil and criminal liability, by fulfilling the legal regulations regarding the environment and other applicable requirements; 
- meeting the financial criteria of various investors;

- reducing costs by reducing energy and raw material consumption, recycling products and packaging, etc.;

- facilitating access to other markets by ensuring compliance with internationally recognized standards on environmental management;

- organizations staffs' awareness on environmental protection;

- clients' requirements satisfaction regarding the certification of the conformity of the suppliers' environmental management system with the applicable standards.

\section{References:}

[1] Cazan G., Environmental Management and Sustainable Development (in Romanian: Managementul mediului si dezvoltarea durabila), XV International Conference "Profesorul Dorin Pavel - fondatorul hidroenergeticii romanesti", Sebes, 2015, pp. 532.

[2] Sorici I., Dumitrascu A.-E., Ciobanu V., Project Management and Sustainable Development (in Romanian: Managementul proiectelor şi dezvoltarea durabilă), Universitatea Transilvania Publishing House, Brasov, 2010.

[3] Dumitrascu A.-E., Environmental Quality Management, Applications (in Romanian: Managementul calitatii mediului. Aplicații), MATRIX ROM Publishing House, Bucharest, 2016.

[4] Susanto A., Mulyono N.B., The transitional Change on the Implementation of ISO 14001:2015 in Copper Ore Mill - Case study, Journal of Ecological Engineering, Vol. 18, No. 5, 2017, pp. 37-49, DOI: $10.12911 / 22998993 / 76210$

[5] International Standard Organization (ISO), Environmental Management System Requirements with Guidance for Use. ISO 14001:2015, Geneva, 2015, https://www.epa.gov/ems/guide-developingenvironmental-management-system-plan

[6] Hammar M., ISO 14001 Requirements and Structure, 2020 https://advisera.com/14001academy/knowledge base/iso-14001-requirements-and-structure/

[7] ISO 14001 Standards: Definition, Examples And Operationalization, https://youmatter.world/en/definition/definition s-iso-14001-standard-csr-definition/

\section{Creative Commons Attribution License 4.0 (Attribution 4.0 International, CC BY 4.0)}

This article is published under the terms of the Creative Commons Attribution License 4.0

https://creativecommons.org/licenses/by/4.0/deed.en_US 